\title{
Promoting Time Management and Self-Efficacy Through Digital Competence in University Students: A Mediational Model
}

\author{
Héctor Galindo-Domínguez \\ Facultad de Educación y Humanidades, Universidad Francisco de Vitoria, Spain \\ ORCID: 0000-0003-0562-160X \\ María José Bezanilla \\ Facultad de Psicología y Educación, Universidad de Deusto, Spain \\ ORCID: 0000-0001-6023-3859
}

Received: 2 Sep 2020

Accepted: 10 Nov 2020

\begin{abstract}
It is though that those students who better manage their time and perceive themselves to be more effective in the tasks they perform are thought to be due, in part, to a stronger understanding and command of digital competence. This competence allows students to know and use a greater number of tools and techniques to respond to the problems that arise in their academic career, favouring the reduction of perceived stress. To test this hypothesis, a total of 200 students from different degrees of Education and universities participated in the study, who answered the Digital Competence Questionnaire in University Students, the Spanish version of Time Management Behaviour Questionnaire, the Scale of Perceived Self-efficacy in academic situations, and the Scale of Global Perception of Stress. The results show how the starting hypothesis is fulfilled in that time management and academic self-efficacy function as mediators between digital competence and types of positive or negative stressors. Finally, these findings implications are discussed.
\end{abstract}

Keywords: digital competence, self-efficacy, time management, stress, university, higher education, technology, ICT

\section{INTRODUCTION}

\section{Digital Competence and its Relationship with Time Management and Self-efficacy}

With the fast advance of technologies, the knowledge society is being forced to adapt and become familiar with increasingly complex codes, but essential to solve increasingly specific problems. In this sense, the digital competence of citizens plays a key role in adapting this process (Ocaña et al., 2019).

Digital competence can be understood as a very useful instrument that allows us to make use of attitudes, knowledge and processes related to information and communication technologies, through which students acquire skills to facilitate the transfer of knowledge and generate innovation (lordache et al., 2017; Krumsvik, 2011; Marza \& Cruz, 2018). More specifically, one of the most widely used theoretical models is the framework proposed by the European Commission known as DigComp, that claims that the digital competence is the sum of the competences related to the knowledge and the usage of the areas related to information, communication and collaboration, creation of digital content, safety and problem solving (Carretero et al., 2017). 
According to various authors (Gisbert \& Esteve, 2011; Neža et al., 2014, among others), the development of this competence is essential in the sense that taking into account the way society interacts in the world of globalization, both our professional environments and our life in general are changing at great rates, requiring training these skills to adapt to the impact that technology is having in these areas (Álvarez et al., 2017).

It is curious to think how the current generation of university students, characterized by being digital natives and having a high degree of affinity with the world of information technology, could present higher levels of digital competence. However, we find that a high percentage of them are not able to extract a significant use of these tools, in part, due to the digital emptiness of the tools they use, really moving away from the best techniques and resources that could be used for academic purposes (Galindo et al., 2017).

Precisely this group of digital natives, easily recognize their usefulness, but at the same time, the great distracting factor and waste of time that they suppose (Saariketo, 2019). Among some of the ways digital applications have to keep their users active, taking them away from the tasks they have to do, are notifications and automatic updates of news and content, to name a few. This continuous information flow makes the user who is not committed to correctly managing their time, fall into the trap of returning to the starting software, and create constant verification cycles (Parviainen, 2016).

This way of interacting with the world of globalization, in which we have a wide variety of tools and information sources at our disposal in a short time, in turn requires strict control of the environment in which these processes take place, since it is very easy to be wrong, deviate and distract, being necessary to effectively manage some limited resources, such as time (Lara, 2005). Some studies already point to how the essential in the field of technology and computers is not the time you spend with them, but the use that is made of them (Álvarez et al., 2019; Fau \& Moreau, 2018). When they are correctly used, as some previous research point out, they contribute to save a significant amount of time, as opposed to if we did not use them (Balasangameshwara, 2015). In this sense, it is considered essential to teach students this type of skills in order to prepare them both for their correct performance in university and for their future professional activity, thus avoiding procrastination, lack of goal setting and lack of organization within multi-tasking, to name a few (Álvarez et al., 2019).

Following this thread, one of the topics that has been repeatedly studied in recent years around digital learning is the topic referring to factors that directly affect the quality and success of technological education (Oliver, 2005). In this line, around the key factors of the students we can find communication with other fellow students, time management, control over time, the pace of learning, motivation, and expectations of efficiency or effectiveness stand out as the most significant (Govindasamy, 2002; Fresen \& Lesley, 2006; Goyal et al., 2010).

What it is more, even now, common digital competence frameworks already begin to exist, in which, at the higher levels ( $\mathrm{C} 2$ ) of this competence, the evaluated person is already asked to make use of technological and non-technological resources, optimizing the time that they use for this purpose to the maximum (INTEF, 2017). This time management should be understood as the effort that students make to organize the use of their time in the most efficient way possible to increase the probability of achieving important educational objectives in a given period of time (Claessens et al., 2007). In other studies, it has already seen in teachers, how those who have been learning about the possibilities offered by new technologies have been able to manage their time better (Şahin, 2014).

In turn, being in possession of this good ability to manage technological and functional resources, such as time, is thought to be linked to a better feeling of efficiency in the task performed; this self-efficacy is understood as the judgment that each person performs on himself based on previous experiences and perceptions about his ability to face a certain task (Bandura, 1982). In this sense, in the last few years, it is being observed how the correct usage of Information and Communication Technologies (henceforth ICT) could lead to an improvement of the academic self-efficacy and achievement through the establishment of a certain limit of time per day (Mandal, 2020). In addition, some of these studies point to the existence of a positive correlation between time management and perceived self-efficacy (Abdul-Hamid \& Ali, 2015; 
Roshanai et al., 2019; Wolters et al., 2017; Zarbakhsh et al., 2015) and even some of them establish a possible causality between both of them in a way that people with worse time management, with poor organizational skills, as well as a poor ability to regulate emotions, can lead to a negative impact in perceived self-efficacy (Roshanai et al., 2019). However, in this sense there are discrepancies with studies who point out that through digital tools, they were able to foster time management in students, but they were not able to improve their self-efficacy or ability of self-regulation of learning (Terry \& Doolittle, 2008).

\section{Stress as Consequence of a Poor Self-management}

Stress is understood as a perception of threat, with the consequent discomfort of anxiety, emotional tension and difficulty in adjusting (Selye, 1976). Among the different types of stress that exist, there are two significant types of stress: eustress and distress. These two types of stress can be understood as a positive response to a stressor and a negative response to a stressor, respectively (McGowan et al., 2006).

Despite the fact that throughout the literature, especially the eustress has been largely ignored, over the years, it has been observed how increasing stress can be beneficial to improve performance up to a certain point. That is why, there are people who experiencing a certain level of stress can work more productively and more efficiently than if the stress was eliminated (Le Fevre et al., 2003; Sajjad, 2017; Selye, 1975; Zajacova et al., 2005). In addition, some other studies point out to a significant and inverse correlation between time management and stress (Hosseini et al., 2013), in a way that good time management skills could reduce significantly the negative effects of stressors (Boyas \& Wind, 2010; Eldeleklioğlu et al., 2010). According to Hosseini et al. (2013) students without any type of objective will not suffer from time problem as they have no intention of moving toward any direction. Nonetheless, also students with faded objectives could be wasting their time. This is why, these authors consider setting clear, measurable, achievable goals within a time limitation is an effective step to manage time that can decrease people's stress.

In the last few years, it has been also observed how there is a correlation and even a positive prediction between self-efficacy and eustress (Measurado et al., 2016; O'Sullivan, 2011), and a negative correlation and causality between self-efficacy and distress (Posada \& Liu, 2017; Siddiqui, 2018), being this model moderated by gender in which female students are more likely to be influenced by academic stress than male students (Posada \& Liu, 2017). This last hypothesis is being still discussed as it has been shown how other studies did not obtain statistically significant differences between self-efficacy and stress (Hernández, 2016). In the same way, it is noteworthy how organizations that foster the well-being of their staff, are indirectly improving their job efficiency and reducing their burnout, stress and anxiety levels (Corrêa, Lopes et al., 2019; Leeanne, 2015; Rahmati, 2015).

\section{Purpose of this Study}

Taking into account all the information collected in the theoretical framework, the purpose of this study is to present a complex psychological model which tries to answer the hypothesis that university students who present better digital competence, better manage their time, and consequently, consider themselves more self-effective, thus reducing negative stress levels and promoting productivity through positive stress levels.

\section{METHODOLOGY}

\section{Sample}

A total of 200 students from degrees related to education participate in this study (Age $=20.46 ; S D=4.44$ ): 41 were students of Early Childhood Education, 154 of Primary Education and 5 of Social Education. 59 of them were in $1^{\text {st }}$ grade, 67 in $2^{\text {nd }}$ grade, 41 in $3^{\text {rd }}$ grade and 33 in $4^{\text {th }}$ grade. Depending on gender, 160 were women and 40 men, and depending on the type of university, 79 came from the public university and 121 from the private university. Finally, 194 of them, have generally face-to-face learning process, 3 of them faceto-face and virtual, and 3 of them merely virtual. 


\section{Instruments}

In order to measure each one of the indicated constructs, specific instruments were used, listed below:

- In order to measure digital competence, the Digital Competence Questionnaire in University Students (Pascual et al., 2019) was used. This questionnaire is made up of a total of 51 items in charge of measuring five dimensions of digital competence: Access to information, communication, creation of contents, safety and problem solving.

- In order to measure Time Management, the Spanish version of the Time Management Behavior Questionnaire (García-Ros \& Pérez-González, 2012) was used. This questionnaire is made up of a total of 34 items in charge of measuring 4 dimensions of time management: Establishment of objectives and priorities, time management tools, preference for the organization, and perception of time control.

- In order to measure academic self-efficacy, the Perceived Self-efficacy Scale in Academic Situations (Palenzuela, 1983) was used. This scale is made up of a total of 10 items in charge of measuring a single dimension: academic self-efficacy.

- In order to measure stress, the Global Stress Perception Scale was used (Guzmán-Yacaman \& ReyesBossio, 2018). This scale is made up of a total of 13 items in charge of measuring two dimensions of stress: negative stress or distress, and positive stress of eustress.

- Finally, students were also asked for some specific contextual variables, among which we highlight gender, degree, type of university, type of education (virtual, blended or face-to-face), age, and grade.

\section{Procedure}

On March 14, 2020, the state of alarm was decreed in Spain in the presence of a pandemic, so all the universities adopted gradual measures to work remotely.

In Mid-April 2020, the present study began to be proposed, at which time the students had already experienced for more than a month what it is to work from home with new technologies.

At this point, a review of the most optimal instruments was carried out in order to achieve the proposed objectives. Once chosen, a database of universities with possible interest in participating was carried out and the questionnaire was distributed online among the teaching staff of these universities, so that they could send it to their students.

Once this data collection process was completed, the data was analysed through SPSS Statistics and SPSS AMOS statistical software.

All this procedure is supported by the dean and the coordinator of the faculty, and complies at all times with ethical principles, as it is a study 1) carried out in adults who do not require to sign an informed consent, 2) voluntary and anonymous, and 3) that allows each participant to leave it when they consider it appropriate. These conditions allow us to eliminate risks and ensure that ethical principles of human research are followed.

\section{Data Analysis}

Initially, the database was built in SPSS Statistics. At this point, the dimensionality of all the selected instruments was studied, in order to obtain the most reliable and valid possible results. For this purpose, firstly, an exploratory factor analysis was carried out, which was then complemented by a confirmatory factor analysis and its parallel study of the model fit for each step done. In this preliminary adjustment phase, the most problematic items for each scale were detected, which were putting the reliability and validity of the data at risk, and they were eliminated from the initial scale, always studying the reliability, the model fit and the explained variance for each step done. 
Table 1. Modification indices and decisions done on the digital competence scale

\begin{tabular}{lcccc}
\hline Step & Item $1\left(\lambda, \alpha_{\mathrm{id}}\right)$ & Item $2\left(\lambda, \alpha_{\mathrm{id}}\right)$ & M. I. & Decision \\
\hline$\# 1$ & $9(.611 ; .737)$ & $10(.548 ; .753)$ & 80.16 & Covariation \\
$\# 2$ & $31(.605 ; .803)$ & $32(.533 ; .814)$ & 83.87 & Covariation \\
$\# 3$ & $39(.689 ; .740)$ & $40(.609 ; .747)$ & 35.02 & Covariation \\
$\# 4$ & $48(.584 ; .778)$ & $49(.591 ; .774)$ & 34.19 & Covariation \\
$\# 5$ & $26(.476 ; .816)$ & $27(.493 ; .815)$ & 29.73 & Item 26 removed \\
$\# 6$ & $44(.705 ; .804)$ & $45(.605: .816)$ & 25.62 & Covariation \\
$\# 7$ & $27(.441 ; .807)$ & $28(.390 ; .806)$ & 31.21 & Item 28 removed \\
$\# 8$ & $42(.583 ; .753)$ & $43(.623 ; .757)$ & 19.46 & Covariation \\
$\# 9$ & $41(.395 ; .764)$ & $42(.513 ; .753)$ & 20.94 & Item 41 removed \\
\hline
\end{tabular}

Once the instruments were optimized, their final internal consistency was continued to be studied, and the correlations between the different dimensions were studied.

Finally, the respective mediation analyses were carried out to respond to the hypothesis of the present study.

\section{RESULTS}

\section{Preliminary Adjustments}

With regard to digital competence scale, despite the fact that initial reliability values were fine, the exploratory factor analysis ( $\mathrm{KMO}=.823 ; \mathrm{p}=.000)$ showed items out of their factor, consequently leading to an improvable variance explained (43.64\% for 5 factors), and improvable model fit $\left(\mathrm{X}^{2} / \mathrm{df}=2.55 ; \mathrm{CFI}=.549\right.$; RMSEA = .088; AIC $=3426.19)$. In order to fix this problem, factorial loadings were studied, opting to delete one by one items $5(\lambda=.375), 11(\lambda=.445), 12(\lambda=.434), 14(\lambda=.438), 18(\lambda=.429), 21(.303), 25(\lambda=.274)$, $27(\lambda=.398), 29(\lambda=.377), 30(\lambda=.406)$ and $50(\lambda=.432)$ as they were considerably lower than the demanded value for researching of $\lambda<.50$ (Awang, 2012). Then, modification indices (M. I.) above 15 were studied (Awang, 2012). In this sense, it was opted to covariate some par of items as they had nice factor loadings and the reliability of the dimension did not improve if the item was deleted $\left(\alpha_{i d}\right)$, and other cases in which it was opted to delete one of the two items by low factorial loading or reliability issues. These decisions are gathered in Table 1.

Finally, item 16 was removed as it covariated highly with items of other dimensions, as items 6 (M. I. = 17.37), 35 (M. I. = 14.36), 44 (M. I. = 17.55) and 48 (M. I. = 15.17). Same situation happened with item 22, which covariated highly with Content Creation dimension (M. I. = 17.47) and item 34 (M. I. = 17.37). After these changes, the variance explained $\left(49.15 \%\right.$ for 5 factors) and model fit $\left(\mathrm{X}^{2} / \mathrm{df}=1.99 ; \mathrm{CFI}=.807\right.$; $\mathrm{RMSEA}=.071$; AIC $=1254.28$ ) improved significantly. The reliability maintained stable and adequate for researching (Access to Information, $\alpha=.783$; Communication, $\alpha=.733$; Content creation, $\alpha=.778$; Safety, $\alpha=.764$; and Problem Solving, $\alpha=$.799).

With regard to time management, also an initial exploratory factor analysis ( $\mathrm{KMO}=.839 ; \mathrm{p}=.000$ ) showed some problematic items. For this scale the initial variance explained $(40.69 \%)$ and the model fit $\left(X^{2} / \mathrm{df}=2.41\right.$; $\mathrm{CFI}=.691 ; \mathrm{RMSEA}=.084 ; \mathrm{AIC}=1083.61)$ were improvable too. Once again, Modification Indices were studied, and it was opted to delete items $6,8,11,24,27,28,32,33$ and 34 as they correlated beyond M. I. > 15 or were totally out of their factor, and opted to covariate ítems 12-23. After these changes, the variance explained (46.68\%) and model fit $\left(\mathrm{X}^{2} / \mathrm{df}=2.09 ; \mathrm{CFI}=.834\right.$; $\left.\mathrm{RMSEA}=.074 ; \mathrm{AIC}=475.48\right)$ improved significantly. The reliability maintained stable and adequate for researching (Establishing objectives and priorities, $\alpha=.809$; Time Management tools, $\alpha=.752$, Preferences for organization, $\alpha=.723$ ).

With regard to academic self-efficacy, the initial exploratory factor analysis (KMO $=.899, \mathrm{p}=.000)$, showed an unique factor explaining the $51.15 \%$ of the variance, an adequate internal consistency $(\alpha=.868)$, and an improvable model fit $\left(\mathrm{X}^{2} / \mathrm{df}=3.04 ; \mathrm{CFI}=.924 ; \mathrm{RMSEA}=.101\right.$; AIC = 165.59). After studying Modification Indices, it was shown how removing item 9, the model improved significantly, explaining the $56.34 \%$ of the 
Table 2. Correlation and reliability matrix

\begin{tabular}{lccccccccccc}
\hline & 1 & 2 & 3 & 4 & 5 & 6 & 7 & 8 & 9 & 10 & 11 \\
\hline INF (1) & $(.783)$ & $.560^{* * *}$ & $.515^{* * *}$ & $.532^{* * *}$ & $.585^{* * *}$ & $.404^{* * *}$ & $.258^{* * *}$ & -.012 & $.300^{* * *}$ & -.005 & $.299^{* * *}$ \\
COM (2) & & $(.733)$ & $.452^{* * *}$ & $.533^{* * *}$ & $.564^{* * *}$ & $.262^{* * *}$ & $.169 *$ & -.068 & $.339^{* * *}$ & .016 & .124 \\
CCR (3) & & & $(.778)$ & $.534^{* * *}$ & $.525^{* * *}$ & $.256^{* * *}$ & $.154^{*}$ & -.013 & $.191^{* * *}$ & -.112 & $.251^{* * *}$ \\
SAF (4) & & & & $(.764)$ & $.672^{* * *}$ & $.245^{* * *}$ & .105 & -.065 & $.328^{* * *}$ & -.016 & $.223^{* * *}$ \\
PRS (5) & & & & & $(.799)$ & $.268^{* * *}$ & $.220^{* * *}$ & -.112 & $.346^{* * *}$ & -.005 & $.200^{* * *}$ \\
EOP (6) & & & & & & $(.809)$ & $.510^{* * *}$ & $.261^{* * *}$ & $.352^{* * *}$ & -.102 & $.795^{* * *}$ \\
TMT (7) & & & & & & $(.752)$ & $.163^{*}$ & .105 & $.155^{*}$ & $.479^{* * *}$ \\
PRO (8) & & & & & & & $(.723)$ & $.166^{*}$ & $-.310^{* * *}$ & $.494^{* * *}$ \\
ASE (9) & & & & & & & & $(.899)$ & $-.238^{* * *}$ & $.361^{* * *}$ \\
DIS (10) & & & & & & & & & $(.863)$ & $-.277^{* * *}$ \\
EUS (11) & & & & & & & & & & $(.853)$ \\
\hline
\end{tabular}

$\mathrm{INF}=$ Access to Information, COM = Communication, CCR = Content Creation, SAF = Safety, PRS = Problem Solving, EOP $=$ Establishing objectives and priorities, $\mathrm{TMT}=$ Time management tools, $\mathrm{PRO}=$ Preferences for organization, $\mathrm{ASE}=$ Academic Self-efficacy, ESN = Distress, ESP = Eustress; ${ }^{*} p<.05 ; * * * p<.01$

variance, with a notorious improvement in the model fit $\left(\mathrm{X}^{2} / \mathrm{df}=2.54 ; \mathrm{CFI}=.954 ; \mathrm{RMSEA}=.088 ; \mathrm{AIC}=122.22\right)$, and an improvement in internal consistency $(\alpha=.899)$.

Finally, with regard to stress, all items were maintained for both factors: distress and eustress. These both factors explained the $56.88 \%$ of the variance and the model fit was of $\mathrm{X}^{2} / \mathrm{df}=2.09 ; \mathrm{CFI}=.939$; RMSEA $=.074$; AIC $=214.35$. Reliability for either distress $(\alpha=.863)$ or eustress $(\alpha=.853)$ was adequate for researching.

After checking the model fit of all instruments used a correlation analysis was carried out. As it is shown in Table 2, significant correlations were found. It is noteworthy to comment that digital competence had a large number of dimensions that correlated significantly with time management dimensions, academic selfefficacy and eustress. It is also remarkable the fact that distress only correlated significantly and negatively with academic self-efficacy $(r=-.238)$ and preferences for organization $(r=-.310)$. For its part, eustress correlated positively and significantly with all studied dimensions, except with communication dimension which was a non-significant correlation $(r=.124)$. Eustress correlated negatively and significantly with distress $(r=-.277)$. Finally, it should be highlighted the high correlation shown between establishing objectives and preferences and problem solving $(r=.795)$.

\section{Mediation Analyses}

In order to measure the mediation impact of time management $\left(M_{1}\right)$ and academic self-efficacy $\left(M_{2}\right)$ between digital competence $(\mathrm{X})$ and stress $(\mathrm{Y})$, two different mediation analyses were carried out: firstly considering distress as dependent variable, and then considering eustress as dependent variable. This decision was taken due to the fact that both types of stress are complementary, but contrary. Hence, it is possible that both types of stress would follow different paths. This process, as said, was done by means of two different mediation analysis.

On the one hand, this first mediation analysis showed significant results in some directs effect, especially, on how digital competence was a good predictor of time management $(B=.267 ; p=.000)$ and academic selfefficacy $(B=.363 ; p=.000)$ but unable to predict distress $(B=.147 ; p=.236)$. With regard to time management only the direct effect towards self-efficacy was statistically significant $(B=.203 ; p=.010)$, since it was unable to predict distress $(B=-.067 ; p=.574)$. Finally, academic self-efficacy inversely and significantly predicted distress $(B=-.367 ; p=.000)$. In relation to indirect effects, two mediation paths resulted statistically significant. Through this analysis, it was shown how the path from digital competence to distress by academic self-efficacy $(B=-.127 ; \mathrm{LL}=-.243 ; \mathrm{UL}=-.043)$ was significant as well as the largest path from digital competence to distress by time management and academic self-efficacy $(B=-.016 ; \mathrm{LL}=-.036 ; \mathrm{UL}=-.003)$ since the zero value is not included within the $95 \%$ confidence interval. This analysis information is gathered in Table 3. 
Table 3. Effects on the mediation analyses

\begin{tabular}{|c|c|c|c|c|c|c|}
\hline Effect & Path & Coeff. & $p$ & SE & LL & UL \\
\hline Direct effect of DC on TM & a1 & .210 & .001 & .064 & .084 & .337 \\
\hline Direct effect of DC on ASE & a2 & .353 & .000 & .071 & .212 & .494 \\
\hline Direct effect of TM on ASE & $\mathrm{d} 21$ & .213 & .006 & .077 & .061 & .365 \\
\hline \multicolumn{7}{|c|}{ Direct, total and indirect effects when distress as predictor } \\
\hline Direct effect of $T M$ on DIS. & b1 & -.055 & .642 & .118 & -.289 & .179 \\
\hline Direct effect of $A S E$ on DIS. & b2 & -.359 & .001 & .107 & -.571 & -.147 \\
\hline Direct effect of $D C$ on $D I S$. & $c^{\prime}$ & .100 & .379 & .114 & -.125 & .326 \\
\hline Total effect of DC on DIS & C & -.054 & .616 & .107 & -.266 & .158 \\
\hline Indirect effect of $D C$ on $D I S$ by TM. & a1b1 & -.011 & (ns) & .029 & -.067 & .048 \\
\hline Indirect effect of DC on DIS by ASE & $\mathrm{a} 2 \mathrm{~b} 2$ & -.127 & (Sig) & .051 & -.243 & -.043 \\
\hline Indirect effect of DC on DIS by TM and ASE. & $\mathrm{a} 1 \mathrm{~d} 21 \mathrm{~b} 2$ & -.016 & (Sig) & .008 & -.036 & -.003 \\
\hline \multicolumn{7}{|c|}{ Direct, total and indirect effects when eustress as predictor } \\
\hline Direct effect of TM on EUS. & b1 & .805 & .000 & .051 & .704 & .906 \\
\hline Direct effect of $A S E$ on EUS. & b2 & .148 & .001 & .046 & .057 & .240 \\
\hline Direct effect of $D C$ on EUS. & $c^{\prime}$ & .057 & .247 & .049 & -.040 & .154 \\
\hline Total effect of DC on EUS. & $\mathrm{C}$ & .286 & .000 & .070 & .146 & .425 \\
\hline Indirect effect of $D C$ on EUS by TM. & a1b1 & .169 & (Sig) & .050 & .074 & .271 \\
\hline Indirect effect of DC on EUS by ASE & $\mathrm{a} 2 \mathrm{~b} 2$ & .052 & (Sig) & .019 & .013 & .091 \\
\hline Indirect effect of DC on EUS by TM and ASE. & $a 1 d 21 b 2$ & .006 & (Sig) & .004 & .001 & .016 \\
\hline
\end{tabular}

Coeff, non-standardized 8 coefficients; SE, standard error; $\mathrm{Cl}$, confidence interval; LL, lower limit; UL, upper limit. ${ }^{*} \mathrm{p}<$ $.05 ;{ }^{* *} \mathrm{p}<.01 ;{ }^{* * *} \mathrm{p}<.00$; (sig.), significant; (ns), non-significant. Conditional indirect effect through pick-a-point technique (-1 SD, Mean, +1 SD). 10,000 bootstrap samples used. DC = Digital Competence; $\mathrm{TM}=$ Time Management; ASE = Academic; Self-efficacy; DIS = Distress; EUS = Eustress.

On the other hand, the second mediation analysis showed significant results in the same way, on how digital competence was a good predictor of time management $(B=.210 ; p=.000)$ and academic self-efficacy $(B=$ $.353 ; p=.000)$ but unable to predict eustress $(B=.057 ; p=.247)$. With regard to time management either, the direct effect towards self-efficacy $(B=.213 ; p=.006)$, or the direct effect towards eustress $(B=.805 ; p=$ $.000)$, were statistically significant.

Finally, academic self-efficacy positively and significantly predicted eustress $(B=.148 ; p=.001)$. In relation to indirect effects, three mediation paths resulted statistically significant. Through this analysis, it was shown how the path from digital competence to eustress by time management $(B=.169$; $\mathrm{LL}=.074 ; \mathrm{UL}=.271)$ was significant as well as the path from digital competence to eustress by academic self-efficacy $(B=.052 ; \mathrm{LL}=$ .013; UL =.091). It is also noteworthy how the largest path from digital competence to distress by time management and academic self-efficacy $(B=.006 ; \mathrm{LL}=.001 ; \mathrm{UL}=.016)$ was also statistically significant, since the zero value was not included within the $95 \%$ confidence interval. All this analysis' information is gathered in Figure 1. 


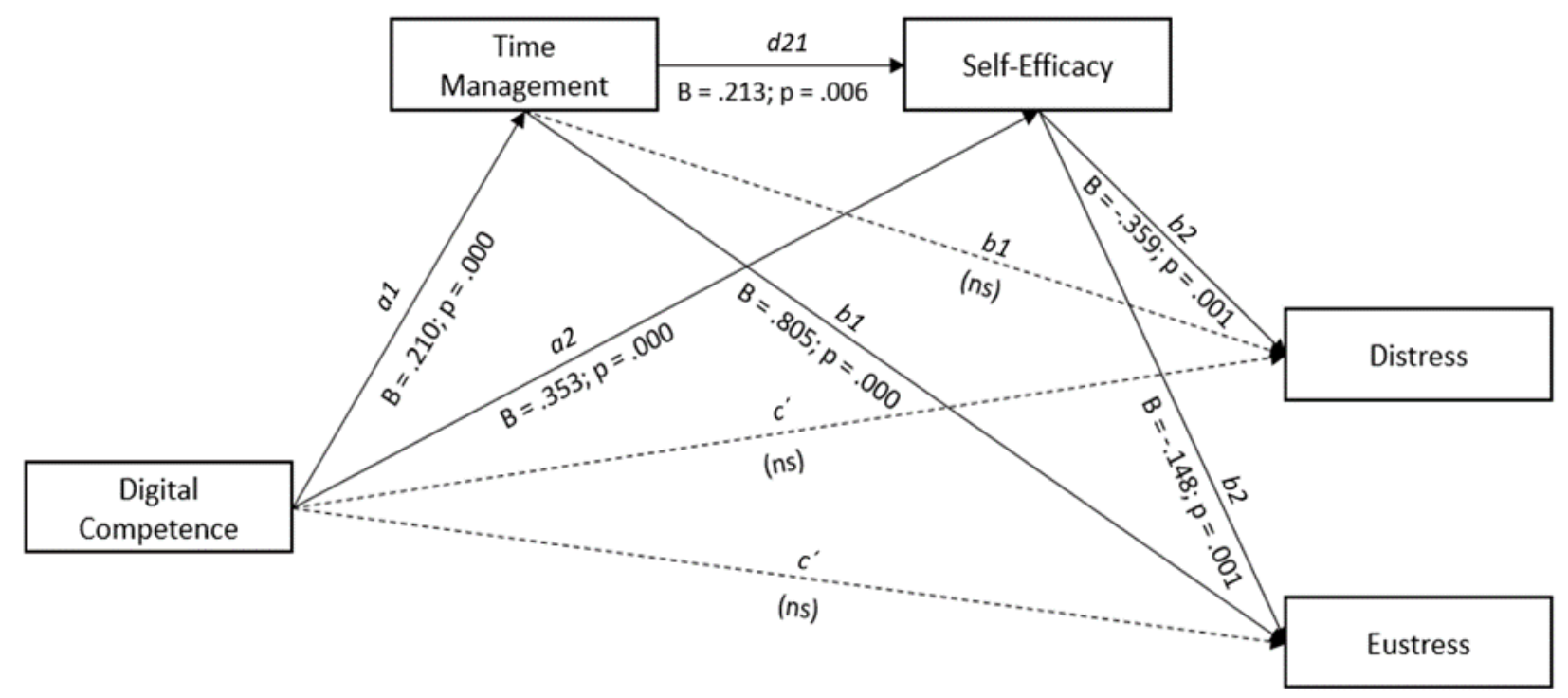

Figure 1. Results of the mediational model with distress and eustress as predictors

\section{DISCUSSION}

The main objective of this study has been to find out the mediating effect of time management and academic self-efficacy between digital competence and the type of stress perceived among university students in the Education degrees. In this sense, we began thinking that those students who managed better their time and perceived themselves as more efficient in their work was, in part, due to they had higher levels of digital competence, as the knowing and using of different technological techniques and tools could support them in the development of better and faster academic tasks. Therefore, this scenario could turn out to be the ideal one to reduce the academic stress of university students.

The analyses carried out show results that fully support this hypothesis, allowing us to confirm that the students' mastery of digital competence has turned out to be a key variable when it comes to having a feeling of controlled emotional exhaustion during the development of their academic career. In view of these data, it can be seen how those people who have a more solid understanding of the use of information and communication technologies for specific purposes (carrying out specific work, searching for specific information, solving a certain problem...), are able to solve their task and manage their time better, feeling themselves as more effective and perceiving less negative stress.

Although previously in the literature there is no mediational model that considers these variables in full, we can see how each of the significant regressions observed has been previously, in part, supported by various studies. Along the showed literature review, we find studies in other social fields that confirm they causality of digital competence on time management (Şahin, 2014), the causality of time management on academic self-efficacy (Roshanai et al., 2019), and even the causality of academic self-efficacy on stress (Measurado et al., 2016; O'Sullivan, 2011; Siddiqui, 2018, among others).

Similarly, it is especially striking to mention one more detail about this mediational model. As previously seen in the literature (Measurado et al., 2016; O'Sullivan, 2011), thanks to this study, we can support the idea that in those cases of people with high time management skills and good self-efficacy, the stress is not a variable that disappears, but rather it is a construct that people can take advantage of, being used as one more mechanism that allows students to be more productive as long as the amount of stress is adequate. This finding is important to consider, since it is an idea that is consistent with other studies (i. e. Burger \& Samuel, 2017), which show that a positive self-efficacy and a reduction in negative stress levels are associated with a better student's well-being, and precisely, this well-being is one of the factors that significantly correlates with academic performance (Bücker, Nuraydin, Simonsmeier, Schneider, \& Luhmann, 2018). 


\section{Theoretical and Practical Implications}

The observed findings of this study have certain theoretical and practical implications. With regard to the theoretical part, these results confirm the mediational power of time management and academic selfefficacy between digital competence and perceived stress, helping to establish more solid conclusions in this theoretical field. Along these lines, in the same way, these results allow us to better understand the role played by each psychological construct studied, serving as the basis for future more complete and complex psychological models. With regard to the practical part, Gisbert et al. (2016) point out that despite having made progress in the matter with the implementation of new university degrees after Bologna process, it is still essential to advance in the design of learning strategies that ensure the acquisition of digital competence in university students. Following this idea, these results show the importance of introducing programs that improve the digital competence of university students, specifically, in order to improve their selfmanagement skills and promote student well-being. In the specific field of education, teachers are expected to work with undergraduate students in the following aspects in a transversal manner at the university instruction (Cabero \& Valencia-Ortiz, 2018; Gisbert \& Lázaro, 2015; Kent \& Giles, 2017): (1) Teach students to learn to identify the objectives and contents of the different curricular areas related to digital competence; (2) Design of teaching-learning activities and situations for the work of digital competence; (3) Select resources and adequate tools for teaching-learning activities and strategies; (4) Share experiences and work collaboratively with other colleagues around digital competence; (5) Discover the applicability of new teaching-learning methodologies through technology. These programs should consist of two parts, a first part of reflection, in which aspects of the education curriculum are reviewed and students are prepared to work on the own program, for instance, by means of self-knowledge and self-evaluation, to subsequently move on to the second point, in which the students begin to analyse digital tools, begin to open their range of ICT resources using and applying them, and begin to consider them as part of the design of teachinglearning activities, within their didactic units. The main objective of these kind of programs should be to prepare university students to be able to analyse, evaluate, select and integrate technology into their daily and professional instruction (Cabero \& Valencia-Ortiz, 2018; Gisbert \& Lázaro, 2015; Kent \& Giles, 2017). By means of this, as previous studies argue, making use of different forms of learning with a variety of technological strategies could serve as an incentive to reach the highest levels of digital competence (Jiménez-Cortés et al., 2017; Rebollo-Catalán et al., 2015). What it is more, according to Instefjord (2015), technology should be better integrated as pedagogical tools for teaching and learning in all subjects in the teacher education programmes.

In this way we can observe the analysed constructs are not statics: it is not only teachers who learn, but students can also be taught to have better digital competence, better time management and better selfefficacy, thanks to the dynamism of these constructs.

In addition, based on previous research, time management and self-efficacy could be improved not only through ICT educational programs as described up to this point, based on the common dimensions of digital competences described in the theoretical framework, but also knowing and being committed to the use of some typical management tools as calendaring software, notes software, email tray system, collaborative features for group assignments, as Google Drive or Dropbox, among others (Rebenich et al., 2010). This type of digital tools could also help students learn to manage themselves better.

\section{Limitations and Prospective}

Finally, it is convenient to highlight some of the major limitations of this research. First, it is necessary to comment on the sample used. It is, somehow, a reduced sample that makes it difficult to draw conclusions that can be extrapolated to the population. This limitation was attempted to be overcome by proposing to participate to more students, and making periodic reminders. However, we must remember that the data was gathered during pandemic times, in which students, on many occasions, had found themselves with a greater teaching load, spending a lot of time in front of the computer screen, and with the final exam date coming up. Hence, participating in any study could have been a less relevant task for them. 
Secondly, the modifications that have been necessary to do to the instruments are highlighted. Despite the fact that in some cases, the instruments presented good reliability, it was observed that in many cases, reliability was not everything, and part of the items of the initial model had to be modified, based on theory, for the sake of improving the model fit. Despite all the modifications, there have been dimensions that, although they have been improved significantly from the beginning, have continued without reaching the most suitable values that the literature recommends in the field of analysis of structural equations (Hooper et al., 2008). These results have made it impossible to enjoy the full validity of the data that would have been expected.

Taking into account all the aforementioned, future studies could try to overcome these limitations and apply this study in other situations where collecting samples is a simpler process, as well as adding to the proposed model other mediating variables that have already been collected in isolation in the literature, such as liking for technology, self-regulation capacity, emotional intelligence, life satisfaction and / or procrastination capacity. Similarly, it may be interesting to test this resulting model in other types of samples as in other fields of knowledge or in other countries.

\section{CONCLUSION}

By and large, as we have studied along these lines, having a high digital competence within university students is a key factor towards developing a positive perception of their time management skills and of their self-efficacy. In the same way, taking advantage of these positive factors permit students to be more productive considering their tasks more a challenge than a threat, and reducing their negative stress levels. Precisely, this research study works as one more evidence of the importance of introducing and carrying out significant educative programmes in which ICT are taken into consideration.

\section{REFERENCES}

Abdul-Hamid, F., \& Ali, M. (2015). The effectiveness of Time Management Strategies instruction on students' academic time management and academic self-efficacy. International Journal of Psycho-Educational Sciences, 4(1), 43-50.

Álvarez, E., Núñez, P., \& Rodríguez, C. (2017). Adquisición y carencia académica de competencias tecnológicas ante una economía digital. Revista Latina de Comunicación Social, 72, 540-559. https://doi.org/10.4185/RLCS-2017-1178

Álvarez, M., Ferrero, A., \& Ugidos, A. (2019). Time management: skills to learn and put into practice. Education + Training, 61(5), 635-648. https://doi.org/10.1108/ET-01-2018-0027

Awang, Z. (2012). A handbook on structural equation modeling using AMOS. Shah Alam, Malaysia: Universiti Teknologi MARA Publication.

Balasangameshwara, J. (2015). Uncovering the Value of ICT in Time Management for Implementation of OBE Courses. Journal of Engineering Education Transformations, 29(1), 43-54. https://doi.org/10.16920/jeet/2015/v29i1/77109

Bandura, A. (1982). Self-efficacy mechanism in human agency. American Psychologist, 37(2), 122-147. https://doi.org/10.1037/0003-066X.37.2.122

Boyas, J., \& Wind, L. H. (2010). Employment-based social capital, job stress, and employee burnout: a public child welfare employee structural model. Children and Youth Services Review, 32(3), 380-388. https://doi.org/10.1016/j.childyouth.2009.10.009

Bücker, S., Nuraydin, S., Simonsmeier, B. A., Schneider, M., \& Luhmann, M. (2018). Subjective well-being and academic achievement: A meta-analysis. Journal of Research in Personality, 74, 83-94. https://doi.org/10.1016/j.jrp.2018.02.007 
Burger, K., \& Samuel, R. (2017). The Role of Perceived Stress and Self-Efficacy in Young People's Life Satisfaction: A Longitudinal Study. Journal of Youth and Adolescence, 46(1), 78-90. https://doi.org/10.1007/s10964-016-0608-x

Cabero, J., \& Valencia-Ortiz, R. (2018). Teacher Education in ICT: Contributions from different Training Models. Revista Caribeña de Investigación Educativa, 2(2), 61-76. https://doi.org/10.32541/recie.2018.v2i2.pp61-76

Carretero, S., Vuorikari, R., \& Punie, Y. (2017). DigComp 2.1: The digital competence framework for citizens with eight proficiency levels and examples of use. Luxembourg, Luxembourg: Publications Office of the European Union.

Claessens, B. C., Van Eerde, W., Rutte, C. G., \& Roe, R. A. (2007). A review of the time management literature. Personnel Review, 36, 255-276. https://doi.org/10.1108/00483480710726136

Corrêa, J. S., Lopes, L. F. D., Almeida, D. M., \& Camargo, M. E. (2019). Workplace wellbeing and burnout syndrome: opposite faces in penitentiary work. Rev. Adm. Mackenzie, 20(3), 1-30. https://doi.org/10.1590/1678-6971/eramg190149

Eldeleklioğlu, J., Yilmaz, A., \& Gültekin, F. (2010). Investigation of teacher trainees' psychological well-being in terms of time management. Procedia - Social and Behavioral Sciences, 2(2), 342-348. https://doi.org/10.1016/j.sbspro.2010.03.022

Fau, S., \& Moreau, Y. (2018). Managing tomorrow's digital skills: what conclusions can we draw from international comparative indicators. Paris, France: United Nations Educational, Scientific and Cultural Organization.

Fresen, J. W., \& Lesley, G. B. (2006). Quality management of e-learning: towards an integrated approach. Paper presented at the FOTIM QA Conference, CSIR, Pretoria 20-22 June 2006.

Galindo, F., Ruiz, S., \& Ruiz, F. (2017). Digital skills before the advent of the Fourth Industrial Revolution. Estudos em Comunicação, 25(1), 1-11.

García-Ros, R., \& Pérez-González, F. (2012). Spanish version of the Time Management Behavior Questionnaire for University Students. The Spanish Journal of Psychology, 15(3), 1485-1494. https://doi.org/10.5209/rev_SJOP.2012.v15.n3.39432

Gisbert, M. \& Esteve, F. (2011). Digital Leaners: la competencia digital de los estudiantes universitarios. La Cuestión Universitaria, 7, 48-59.

Gisbert, M., \& Lázaro, J. L. (2015). Professional development in teacher digital competence and improving school quality from the teachers' perspective: a case study. New approaches in Educational Research, 4(2), 115-122. https://doi.org/10.7821/naer.2015.7.123

Gisbert, M., González, J., \& Esteve, F. (2016). Competencia digital y competencia digital docente: una panorámica sobre el estado de la cuestión. Revista Interuniversitaria de Investigación en Tecnología Educativa, 0, 74-83. https://doi.org/10.6018/riite2016/257631

Govindasamy, T. (2002). Successful implementation of elearning: pedagogical considerations. Internet and Higher Education, 4, 287-299. https://doi.org/10.1016/S1096-7516(01)00071-9

Goyal, E., Purohit, S., \& Bhagat, M. (2010). Factors that affect Information and Communication Technology usage: A case Study in Management Education. Journal of Information Technology Management, 21(4), 38-57.

Guzmán-Yacaman, J. E., y Reyes-Bossio, M. (2018). Adaptación de la Escala de Percepción Global de Estrés en estudiantes universitarios peruanos. Revista de Psicología, 36(2), 719-750. https://doi.org/10.18800/psico.201802.012 
Hernández, L. F. (2016). The Evolution of Academic Self-Efficacy and Academic Stress on the University Students in Mexico. American Journal of Educational Research, 4(7), 556-562.

Hooper, D., Coughlan, J., \& Mullen, M. R. (2008). Structural Equation Modelling: Guidelines for Determining Model Fit. Electronic Journal of Business Research Methods, 6(1), 53-60.

Hosseini, S., Nourbakhsh, P., \& Sepasi, H. (2013). Relationships between time management and job stress. Archives of Applied Science Research, 5(1), 301-307.

Instefjord, E. (2015). Appropriation of Digital Competence in Teacher Education. Nordic Journal of Digital Literacy, 10, 313-321.

INTEF. (2017). Common digital competence framework for teachers. Madrid, Spain: Ministerio de Educación, Cultura y Deporte.

Iordache, C., Mariën, I., \& Baelden, D. (2017). Developing Digital Skills and Competences: A QuickScan Analysis of 13 Digital Literacy Models. Italian Journal of Sociology of Education, 9(1), 6-30. https://doi.org/10.14658/pupj-ijse-2017-1-2

Jiménez-Cortés, R., Vico-Bosch, A., \& Rebollo-Catalán, A. (2017). Female university student's ICT learning strategies and their influence on digital competence. International Journal of Educational Technology in Higher Education, 14, 10. https://doi.org/10.1186/s41239-017-0040-7

Kent, A. M., \& Giles, R. M. (2017). Preservice teachers' technology self-efficacy. SRATE Journal, 26(1), 9-20.

Krumsvik, R. J. (2011). Digital competence in Norwegian teacher education and schools. Hogre utbildning, 1(1), 39-51.

Lara, P. (2005). Use of digital content: information technologies, knowledge society and university. Journal of University and Knowledge Society, 2(2), 1-5. https://doi.org/10.7238/rusc.v2i2.257

Le Fevre, M., Matheny, J., \& Kolt, G. (2003). Eustress, distress, and interpretation in occupational stress. Journal of Managerial Psychology, 18, 726-744. https://doi.org/10.1108/02683940310502412

Leeanne, E. (2015). Examining the impact of job burnout on the health and well-being of human service workers: a systematic review and synthesis. Human Service Organizations: Management, Leadership \& Governance, 39, 167-181. https://doi.org/10.1080/23303131.2015.1014122

Mandal, S. (2020). ICT Exposure and Its Relationship with Academic Self-efficacy and Achievement of Adolescent Students: The Field-Level Study in India and Fiji. In: D. Maiti, F. Castellacci, \& A. Melchior (eds), Digitalisation and Development (pp. 407-434). Singapore, Republic of Singapore: Springer. https://doi.org/10.1007/978-981-13-9996-1_16

Marza, M., \& Cruz, E. (2018). Gaming como Instrumento Educativo para una Educación en competencias Digitales desde los Academic Skills Centres. Revista General de Información y Documentación, 28(2), 489-506. https://doi.org/10.5209/RGID.60805

McGowan, J., Gardner, G., \& Fletcher, R. (2006). Positive and negative affective outcomes of occupational stress. New Zealand Journal of Psychology, 35, 92-98.

Measurado, B., Richaud, M. C., \& Mateo, N. J. (2016). Engagement, Flow, Self-Efficacy, and Eustress of University Students: A Cross-National Comparison Between the Philippines and Argentina. The Journal of Psychology, 150(3), 281-299. https://doi.org/10.1080/00223980.2015.1024595

Mumtaz, S. (2000). Factors affecting teachers' use of information and communications technology: a review of the literature. Journal of Information Technology for Teacher Education, 9(3), 319-342, https://doi.org/10.1080/14759390000200096 
Neža, B., Ferrari, A., \& Punie, Y. (2014). DIGCOMP: a Framework for Developing and Understanding Digital Competence in Europe. eLearning Papers, 38, 3-17. https://doi.org/10.2788/52966

O'Sullivan, G. (2011). The Relationship Between Hope, Eustress, Self-Efficacy, and Life Satisfaction Among Undergraduates. Social Indicators Research, 101, 155-172. https://doi.org/10.1007/s11205-010-9662-z

Ocaña, Y., Valenzuela, L., \& Garro, L. (2019). Inteligencia artificial y sus implicaciones en la educación superior [Artificial intelligence and its implications in higher education]. Propósitos y Representaciones, 7(2), 536-568. https://doi.org/10.20511/pyr2019.v7n2.274

Oliver, R. (2005). Strategies for Assuring the Quality of Online Learning in Australian Higher Education. In M. Wallace, A. Ellis, \& D. Newton (Eds), Proceedings of Moving Online II Conference (pp. 222-231). Massachusetts, United States: Academic Press.

Palenzuela, D. (1983). Construcción y validación de una escala de autoeficacia percibida específica de situaciones académicas [Construction and validation of a scale of perceived self-efficacy specific to academic situations]. Análisis y Modificación de Conducta, 9(21), 185-219. https://doi.org/10.33776/amc.v9i21.1649

Parviainen, J. (2016). Quantified Bodies in the Checking Loop: Analyzing the Choreographies of Biomonitoring and Generating Big Data. Human technology, 12(1), 56-73. https://doi.org/10.17011/ht/urn.201605192620

Pascual, M. A., Ortega-Carrillo, J. A., Pérez-Ferra, M., \& Fombona, J. (2019). Competencias digitales en los estudiantes del grado de maestro de educación primaria. El caso de tres universidades españolas. Formación Universitaria, 12(6), 141-150. https://doi.org/10.4067/S0718-50062019000600141

Posada, A., \& Lu, Y. (2017). The Moderating Effects of Gender on the Relationship between Academic Stress and Academic Self-Efficacy. International Journal of Stress Management, 25(1), 56-61. https://doi.org/10.1037/str0000089

Rahmati, Z. (2015). The study of academic burnout in students with high and low level of self-efficacy. Procedia - Social and Behavioural Sciences, 171, 49-55. https://doi.org/10.1016/j.sbspro.2015.01.087

Rebenich, T., Gravell. A., \& Tiropanis, T. (2010). Survey of students' technology use for time management. In J. Herrington \& C. Montgomerie (Eds.), World Conference on Educational Multimedia, Hypermedia \& Telecommunications. Association for the Advancement of Computing in Education, Toronto, Canada.

Rebollo-Catalán, A., Vico-Bosch, A., \& García-Pérez, R. (2015). Women's learning of social networks and their influence on digital competence. Prisma Social, 15, 122-146.

Roshanai, H., Gunnel, J., Suzanne, W., \& Lomqvist, L. (2019). Time management skills in relation to general self-efficacy and parental sense of competence in individuals with and without cognitive disabilities. Cogent Psychology, 6(1), 1-16. https://doi.org/10.1080/23311908.2019.1655981

Saariketo, M. (2019). Encounters with Self-Monitoring Data on ICT Use. Nordicom Review, 40(1), 125-140. https://doi.org/10.2478/nor-2019-0018

Şahin, A. (2014). The Role of Information and Communication Technologies in Schools: Perspectives of Teachers. International Journal of Academic Research in Progressive Education and Development, 3(2), 112-124. https://doi.org/10.6007/IJARPED/v3-i2/919

Sajjad, S. M. (2017). Stress and Time Management. In S. M. Sajjad (coord.), Essentials of Counseling (pp. 206248). Dacca, Bangladesh: Abosar Prokashana Sangstha.

Selye, H. (1975). Stress without distress. Pennsylvania, USA: Lippincott Publishing. https://doi.org/10.1007/978-1-4684-2238-2_9

Selye, H. (1976). Stress in Health and Disease. Massachusetts, USA: Butterworth. 
Siddiqui, A. F. (2018). Self-efficacy as a predictor of stress in medical students of King Khalid University, Saudi Arabia. Makara Journal of Health Research, 22(1), 1-7. https://doi/org/10.7454/msk.v22i1.7742

Terry, K. P., \& Doolittle, P. E. (2008). Fostering self-efficacy through time management in an online learning environment. Journal of Interactive Online Learning, 7(3), 195-207.

Wolters, C. A., Won, S., \& Hussain, M. (2017). Examining the relations of time management and procrastination within a model of self-regulated learning. Metacognition Learning, 12, 381-399. https://doi.org/10.1007/s11409-017-9174-1

Zajacova, A., Lynch, S. M., \& Espenshade, T. J. (2005). Self-efficacy, stress, and academic success in college. Research in Higher Education, 46, 677-706. https://doi.org/10.1007/s11162-004-4139-z

Zarbakhsh, M., Akram, S., Rahmani, M., Mazloumi, M., \& Kiani, E. (2015). The relationship between time management, self-efficacy and entrepreneurship among students. European Online Journal of Natural and Social Sciences, 4(1), 211-218.

Correspondence: Héctor Galindo-Domínguez, Universidad Francisco de Vitoria, Spain. E-mail: hector.galindo@ufv.es 